\title{
Urinary pyridinoline cross-links as biomarkers of osteogenesis imperfecta
}

\author{
Uschi Lindert', Marius Kraenzlin², Ana Belinda Campos-Xavier, Matthias R. Baumgartner', Luisa Bonafé3, \\ Cecilia Giunta $^{1 *}$ and Marianne Rohrbach ${ }^{1}$
}

\begin{abstract}
Osteogenesis imperfecta (OI) is a group of genetic heterogeneous connective tissue disorders characterized by increased bone fragility and susceptibility to fractures. Laboratory diagnosis relies on time-consuming and cost-intensive biochemical and molecular genetics analyses. Therefore, it is desirable to identify and establish new diagnostic markers for OI that are reliable, cost-effective and easily accessible. In our study we have identified the ratio of the urinary pyridinoline cross-links lysyl-pyridinoline and hydroxylysyl-pyridinoline as a promising, time- and cost-effective biomarker for osteogenesis imperfecta, that could be used furthermore to investigate cases of suspected non-accidental injury in infants.
\end{abstract}

Keywords: Osteogenesis imperfecta, Biomarker, Urinary pyridinoline cross-links, LP/HP ratio, Collagen, Mutations, Non-accidental injury

\section{Dear Editor,}

Osteogenesis imperfecta or "brittle bone disease" (OI) is a clinically and genetically heterogeneous disorder of bone matrix formation and remodelling, presenting with low bone mass, bone fragility and deformity, short stature, grey or blue sclera, and hearing loss. Its prevalence is about 1 in 15,000 to 20,000 births [1]. Approximately $90 \%$ of OI cases are caused by dominant mutations in COL1A1 and COL1A2 resulting in quantitative and/or qualitative alterations of type I collagen, the major extracellular matrix component of bone and skin. A proportion of the remaining $10 \%$ is due to either dominant or recessive mutations in several noncollagenous genes involved in the post-translational processing of procollagen I, in intracellular collagen transport, in osteoblast-specific signaling or in gene regulation [2].

Diagnosis of OI and identification of the diseasecausing gene is important i) to end the patient's quest for the disease causing his or her symptoms; ii) to allow for prenatal diagnosis, iii) to clarify cases of suspected "non-accidental injury" or "battered child syndrome"; iv)

\footnotetext{
* Correspondence: Cecilia.Giunta@kispi.uzh.ch

'Division of Metabolism, Connective Tissue Unit, University Children's Hospital Zurich and Children's Research Centre, Zurich, Switzerland

Full list of author information is available at the end of the article
}

and to investigate the underlying pathomechanism in order to develop new therapeutic approaches. Establishing a specific diagnosis currently relies on biochemical analysis of collagens secreted by cultured fibroblast obtained by skin biopsies, and on molecular genetic analysis of the known OI related genes. The accessibility of modern genomic sequencing technologies has reduced the cost of molecular genetic testing, which was almost prohibitive in the past, due to the large number of genes, and exons per gene, to be sequenced. However, the interpretation of the molecular testing often requires biochemical investigations aimed to infer pathogenecity to the identified sequence variant if it is not yet reported on specialized mutation data bases such as the Database of Osteogenesis imperfecta variants at http://www.le.ac.uk/genetics/collagen/. Therefore, the cost remains a hurdle in OI diagnostics.

The urinary cross-links lysyl-pyridinoline (LP, or deoxypyridinoline DPD) and hydroxylysyl-pyridinoline (HP, or pyridinoline PYD) are established biochemical markers of osteoclastic bone resorption and collagen degradation. Pyridinolines are formed during fibril formation of type I and type II collagen in the extracellular matrix. Some lysyl- and hydroxylysyl-residues in distinct positions in the 
collagen triple-helix and in the telopeptides of the tropocollagen are oxidised by lysyl oxidase. Subsequently three of these residues are covalently linked thereby interconnecting tropocollagen molecules and stabilizing the collagen matrix. When bone collagen is degraded, pyridinolines remain as stable degradation products and are secreted with the urine. Depending on whether or not these lysyl residues had been hydroxylated prior to crosslinking, lysyl-pyridinoline (LP) or hydroxylysyl-pyridinoline (HP) is generated. Although LP and HP values in the urine vary substantially depending on age and time of sampling, their ratio is remarkably constant (LP/HP: $0.2+0.03)$ in healthy individuals at any age [3]. Furthermore, LP/HP ratios are proven diagnostic tools for genetic disorders of collagen metabolism such as the kyphoscoliotic type of EhlersDanlos syndrome (EDS VIA) [4].

Since both dominant and recessive forms of OI lead to abnormal cross-linking chemistry in bone collagen [5], we hypothesize that the urinary LP/HP ratio may serve as a diagnostic biomarker for OI.

\section{Methodology}

The study was conducted according to the declaration of Helsinki, and approved by SwissEthics. To test whether the ratio of urinary pyridinolines LP/HP may be used as a biomarker for OI, we measured LP and HP cross-links by automated HPLC [3] in spot urines of 49 genetically defined OI patients. The study cohort included patients with mutations in the following genes: COL1A1 or COL1A2 ( $n=24$; including 6 patients aged 0.1-24 months), LEPRE1 $(n=8)$, CRTAP $(n=4), \operatorname{SP7/OSX}(n=1)$, BMP1/mTLD $(n=2)$, SERPINF1 $(n=2)$, the recurrent c. $-14 \mathrm{C}>\mathrm{T}$ in IFTM5 $(n=3), \operatorname{WNT1}(n=1), \operatorname{PLOD} 2(n=1)$ and $\operatorname{FKBP} 10(n=3)$, as well as heterozygous carriers for mutations in LEPRE1 $(n=2)$, CRTAP $(n=2)$ and SP7/OSX $(n=2)$.

\section{Findings}

$\mathrm{LP} / \mathrm{HP}$ ratios are shown in Fig. 1. Compared to control $\mathrm{LP} / \mathrm{HP}$ ratios $(0.20 \pm 0.03, n=325)$ [3], we found (i) markedly decreased LP/HP ratios in OI patients with mutations in LEPRE1 (mean: 0.11), in CRTAP (mean: 0.106), in SP7/OSX (0.086) and in IFTM5 (mean: 0.095); (ii) moderately decreased ratios in patients with mutations in FKBP10 (mean: 0.128), in WNT1 (0.126), as well as in heterozygous carriers for a mutation in SP7/OSX (mean: 0.128); (iii) normal LP/HP ratios in patients with mutations in SERPINF1 (mean: 0.195), in BMP1/mTLD (mean: 0.226), and in heterozygous carriers for LEPRE1 (mean: 0.2) and CRTAP (mean: 0.172) mutations. In patients with COL1A1/COL1A2 mutations (mean: $0.184 ; n=24)$, the LP/HP ratios were normal in $15 / 24$, decreased in $8 / 24$ and increased in $1 / 24$. 6 out of 8 patients presenting with decreased LP/HP ratios were

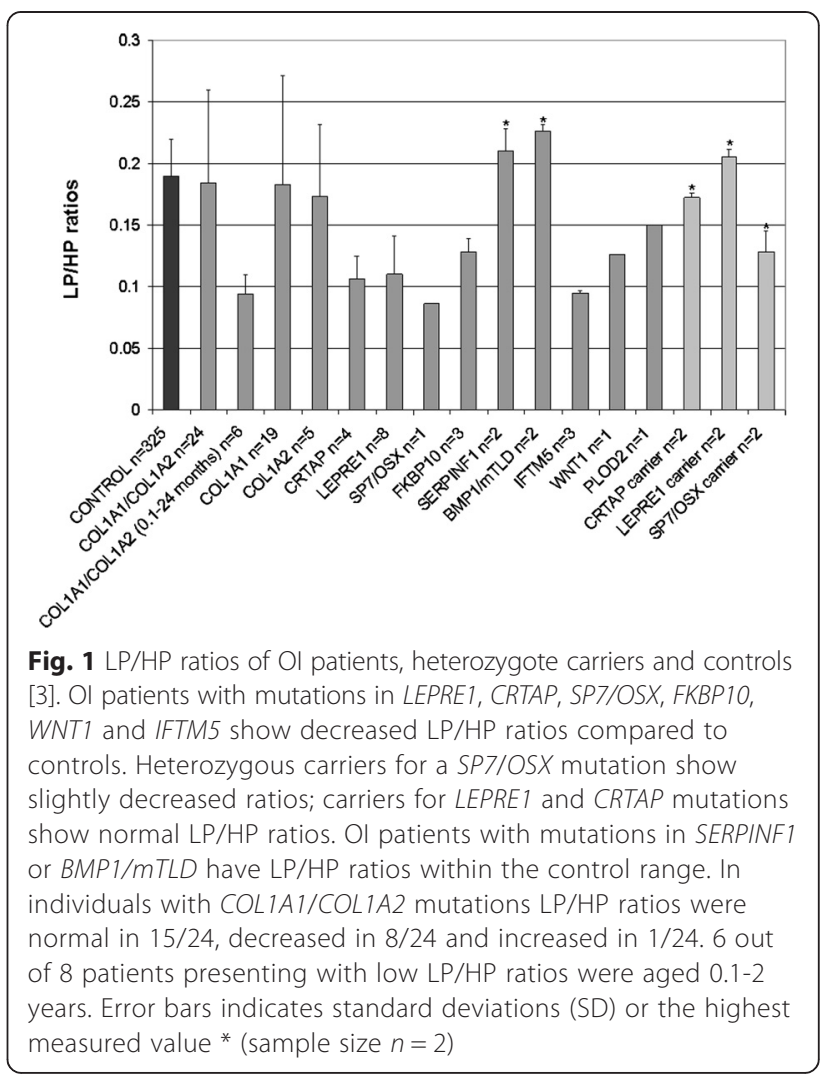

aged 0.1-2 years (normal values: $0.172 \pm 0.02$, age $1-12$ months; $0.193 \pm 0.03$, age 1-3 years) [3].

Bisphosphonate treatment did not influence the ratio of total urinary pyridinoline cross-links (data not shown).

\section{Conclusions}

These results identify the urinary pyridinoline ratio LP/ HP as a promising biomarker for some forms of OI. In particular, it has the potential to detect recessive forms of OI caused by mutations in the genes LEPRE1, CRTAP, FKBP10, WNT1 and SP7/OSX, and to discriminate between the dominant inherited forms caused by COL1A1/ COL1A2 and IFTM5 mutations, therefore improving the efficacy of the final diagnosis and reducing the time and costs of laboratory investigations. Furthermore, the urinary LP/HP ratios might be helpful in investigating cases of suspected non-accidental injury in babies and infants aged 2 years and below.

More samples will be needed to establish urinary pyridinolines as a screening tool for OI diagnostics. Therefore, with this report we hope to attract more cases of OI with a known genetic defect in order to statistically validate our preliminary study.

\section{Abbreviations}

DPD: deoxypyridinoline; HP: hydroxylysyl-pyridinolines; LP: lysyl-pyridinolines; Ol: osteogenesis imperfecta; PYD: pyridinoline. 
Authors' disclosures or potential conflicts of interest

All authors declare that they have no conflicts of interest with the contents of this article. All authors have read and agreed to the content of the manuscript and all authors are included on the author list.

\section{Authors' contributions}

CG, MR and UL designed the study and wrote the paper. All authors have contributed to drafting or revising the article for intellectual content, and have approved the final version of the manuscript.

\section{Acknowledgements}

We are most grateful to Profs. B. Steinmann, I. Kennerknecht, F. Rutsch, Ch. Netzer, VL. Ruiz-Perez, N. Elcioglu, M. Janner, B. Steiner, S. Temtami, M. Aglan, D. Sillence, EM. Abdalla, for contributing to this study with patient samples. We thank Angelika Schwarze and Christine Plüss for expert technical assistance, and Dr. Sofie Symoens, Center for Medical Genetics Ghent, for communicating molecular genetic findings of some patients.

\section{Funding sources}

The work was supported by the Swiss National Science Foundation (SNF Grant Nr. 310030_138288) and the Gottfried und Julia Bangerter-RhynerStiftung to CG and MR.

\section{Author details}

'Division of Metabolism, Connective Tissue Unit, University Children's Hospital Zurich and Children's Research Centre, Zurich, Switzerland. ${ }^{2}$ Clinic for Endocrinology, Diabetology and Metabolism, University Hospital, Basel, Switzerland. ${ }^{3}$ Center for Molecular Diseases, Lausanne University Hospital, Lausanne, Switzerland.

Received: 18 June 2015 Accepted: 30 July 2015

Published online: 27 August 2015

\section{References}

1. Marini JC. Nelson textbook of pediatrics. Philadelphia: Saunders; 2004. p. 2336-38.

2. Lindert U, Weis MA, Rai J, Seeliger F, Hausser I, Leeb T, et al. Molecular Consequences of Defective SERPINH1/HSP47 in the Dachshund Natural Model of Osteogenesis Imperfecta. J Biol Chem. 2015. doi:10.1074/ jbc.M115.661025.

3. Kraenzlin ME, Kraenzlin CA, Meier C, Giunta C, Steinmann B. Automated HPLC assay for urinary collagen cross-links: effect of age, menopause, and metabolic bone diseases. Clin Chem. 2008;54(9):1546-53. doi:10.1373/clinchem.2008.105262.

4. Steinmann B, Eyre DR, Shao P. Urinary pyridinoline cross-links in Ehlers-Danlos syndrome type VI. Am J Hum Genet. 1995;57(6):1505-8.

5. Eyre DR, Weis MA. Bone collagen: new clues to its mineralization mechanism from recessive osteogenesis imperfecta. Calcif Tissue Int 2013;93(4):338-47. doi:10.1007/s00223-013-9723-9.

\section{Submit your next manuscript to BioMed Central and take full advantage of:}

- Convenient online submission

- Thorough peer review

- No space constraints or color figure charges

- Immediate publication on acceptance

- Inclusion in PubMed, CAS, Scopus and Google Scholar

- Research which is freely available for redistribution 